\title{
LIDAR DATA ANALYSES FOR ASSESSING THE CONSERVATION STATUS OF THE SO-CALLED BATHS-CHURCH IN HIERAPOLIS OF PHRYGIA (TR)
}

\author{
C. Marson ${ }^{1}$, G. Sammartano ${ }^{2}$, A. Spanò ${ }^{2} *$, M.R. Valluzzi ${ }^{3}$ \\ ${ }^{1}$ Department of Civil, Architectural and Environmental Engineering, University of Padova, Via Marzolo 9, 35131 Padova (Italy) \\ claudia.marson@ dicea.unipd.it \\ ${ }^{2}$ Department of Architecture and Design (DAD) - Politecnico di Torino, Viale Mattioli 39, 10125 Torino (Italy) \\ giulia.sammartano@polito.it; antonia.spanò@polito.it \\ ${ }^{3}$ Department of Cultural Heritage, University of Padova, Piazza Capitaniato 7, 35139 Padova (Italy) \\ mariarosa.valluzzi@unipd.it
}

KEY WORDS: LiDAR Data, 3D models, feature detection, structural assessment, damages, decay, cracks detection

\begin{abstract}
:
The LiDAR technology has aroused considerable interest in the field of structural study of historical buildings, aimed at the structural assessment in the presence of different states of stresses and at the evaluation of the health status.

The interest is due mostly by the ability of generating models of the built structures being able to predetermine different levels of schematization, two-dimensional and three-dimensional, in order to be able to perform evaluation processes assigning simplified geometric contents that correspond to the physical reality of the artefacts.

This paper intends to report some results of these experiences applied in archaeological domain, to the so-called Baths-Church at Hierapolis in Phrygia (Pamukkale, TR). In particular, the generation of accurate models from dense clouds and their reduction to models with simplified geometries too, is explored, with the further aim of testing automated strategies for features detection and editing process that leads to appropriate models for visual and analytical structural assessment. The accuracy and density parameters of the LiDAR clouds will be analysed to derive orthophotos and continuous mesh models, both to obtain the best results from the application of research algorithms such as region growing to detect blocks, and to allow visual analysis on digital models and not on site.

The ability to determine with high accuracy both the size and the anomalies of the wall systems (out of plumb and other rotation or local mechanisms of collapse), together with the possibility of identifying the lay of the individual drywall blocks and also the signs of cracks and collapses, allow deriving suitable models both for FE (Finite Elements) analysis and DE (Discrete Elements) analysis, as well as analytical ones.
\end{abstract}

\section{INTRODUCTION}

The structural evaluation of an artefact, such as a building, its parts or, more often in the archaeological field, its remains, starts from the knowledge of all its features. The current configuration is the results of many factors, starting from the way it was built, the materials applied and, during the centuries, the human or natural alterations or actions on it. The survey plays a fundamental role in understanding the actual history undergone by the building. It is developed through three different levels of examinations aimed at: i) obtaining the geometrical (i.e., architectural) representation of a threedimensional virtual model, ii) identifying all the structural features developed during its construction or modification, iii) analysing its state of conservation in term of degradation, crack patterns, etc. (D.P.C.M. 9.02.2011). In such a context, 3D range and image-based survey is fundamental to reach the most effective representation of the case study, thus giving the geometrical base for the engineering processes. (Korumaz et al. 2017; Shrestha et al. 2017; Guardini, 2014) and morphological analysis (Teza et al. 2016).

Both the side of digital photogrammetry technologies and that of terrestrial laser scanning (TLS), and above all their integration, of which the advantage has been fully recognized, are based on a high productivity of data acquisition, accurate dense and three-dimensional. They allow for setting up a 3D digital archive from which to select and process subsequent elaborations, so that survey products such as 2D and 3D digital models and orthophotos can be derived.
Nevertheless, the implementation of numerical and analytical models is the consequence of a cluster of onsite activities followed by in lab evaluations.

Especially in presence of complex architectural object, the procedures for transforming the 3D points cloud model to threedimensional finite elements models (FEM) has been largely inquired, mostly to evaluate the main structural features of the ancient or historic buildings (Castellazzi et. al. 2015; Custodi \& Scaia, 2016) and to appraise the static vulnerability till the overall seismic assessment (Pieraccini et al. 2014),

However, dealing with structures made by blocks, although a complete knowledge of elements dimensions cannot be achieved, inner parts of walls also need to be investigated to properly feed distinct element models (DEM).

The present paper focuses on the process that is placed between the phase of the geometrical/structural data acquisition and its numerical development. The survey method is here applied to the case study of the Baths-Church in Hierapolis of Phrygia (Pamukkale, Turkey). Its remains are located in an area often stricken by earthquakes of medium-high intensity.

\section{DIFFERENT SENSOR-BASED POINTS MODELS: DESCRIPTIVE CAPABILITIES}

There are countless studies and tests carried out to identify the degree of accuracy and the descriptive capabilities of LiDAR and photogrammetric surveys, the latter being benefited today from the Structure from Motion (SfM) technique derived from the computer vision, that allows the generation of dense and accurate clouds in a rapid and low cost manner. (Adamopoulos 
et al., 2017, Escarcena et al, 2011, Pierrot-Deseilligny et al. 2011, Remondino, 2011, Patias, Grussenmeyer, Hanke, 2008).

Considering that the LiDAR clouds can be recorded with RMSe close to few millimetres, and that the orthophotos can derive from photogrammetric oriented blocks with the same accuracy, and considering that orthophotos can easily present resolutions equal to $1 \mathrm{~mm}$ (figure 5), thanks to today's sensors, it is quite evident that they enable to analyse the morphological aspects of buildings and architectural elements, adding to materials and their degradation (Sammartano \& Spanò, 2017). The latter can be plotted in the various forms: degradation and cracking pattern, progression of lesions, gaps, and detachments.

However, the current challenge in recent years has certainly shifted to the possibilities offered, by algorithms and methods, to extract information from point clouds or image analysis in an automatic way.

Sensor-based point clouds and mesh, as well as its treatment and processing can differently contribute to the morphological descriptive value of the 3D model. There are many variables in the use of different sensors, and thus derived orthoimages, and meshed 3D models.

Automatic and semi-automatic segmentation methods, developed to be applied in many sectors and for different purposes, can be classified into two large categories, basing the segmentation on different approach:

- radiometric features, image processing and segmentation

- geometric features, surface analysis and local curvature for discontinuities detection

In the domain of built heritage conservation, the main aim of developed methods is to provide more accurate and effective solutions in term of time and cost, for materials and pathologies mapping.

Basically image-based segmentation takes advantages from grouping similar pixels in an image using edge-based or regionbased strategies. For the first family of method the assumption is to detect discontinuities, while the second approach is based on similarities involving methods of thresholding, region growing, clustering. The masonry delineation of the built heritage has certainly not been the first for which these methods have been developed, but there are studies that have demonstrated the effectiveness of the classification using RGB close range images and Artificial Intelligence techniques (Oses et al, 2014), or exploiting near-infrared and multispectral imagery (Lerma 2005), or even using signal analysis (2D Continuous Wavelet Transform) applied to TLS data (Valero et al., 2018).

On the other hand, segmentation of LiDAR data is one of the fundamental procedure of point cloud automated process. Various technique have been developed mostly in the field of buildings and roofs extraction from airborne points cloud through planes, lines and points detection (Auer \& Hinz, 2007). Region growing method is well established and widespread to obtain the goal of segmentation, clustering points with similar attributes into homogenous regions. A segmentation of planar patches based on cluster analysis applied on buildings and using TLS data can be found in Lari et al. (2011); more close to the field of delineation and digitization of (block) masonries structures, is the work of Riveiro et al. (2015), who propose an algorithm operating on 2D intensity images extracted from LiDAR data.

\section{CASE STUDY: THE SO-CALLED BATHS-CHURCH}

The so-called Baths-Church in Hierapolis of Phrygia (figure 1a) are the results of many construction phases, starting from the
Roman period (II or III cent. C.A.), when they were used as a public building (firstly incorrectly identified as Baths) made of huge travertine blocks (many of them longer than a meter). (Verzone 1956. D’Andria 2015)

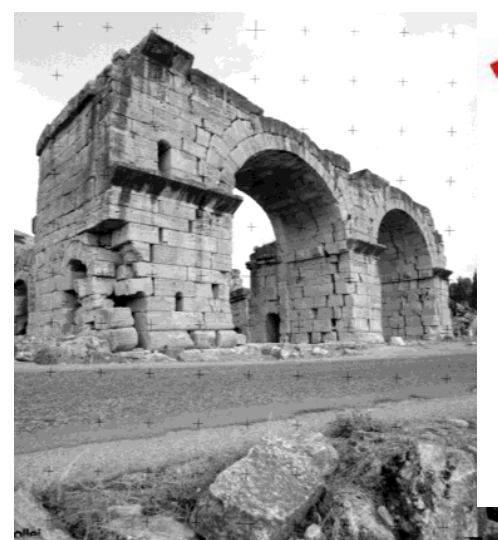

(a)

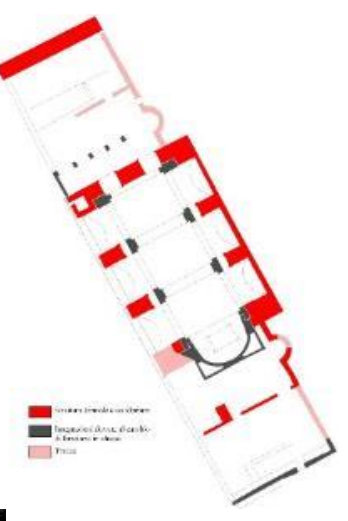

(b)
Figure 1. (a) An archive photogram of the west front (acquired in 1997 - Politecnico di Torino) b) Schematic representation of roman public building (red) turning into the Byzantine church (added structures in grey).

In plan, the complex was oriented northwest-southeast direction and it included a central main hall covered by a barrel vault of about $19 \mathrm{~m}$ of span, borne for each side by a series of further three vaults, supported by four massive pillars (the smallest had $5 \times 3 \mathrm{~m}$ section in plan). Regular blocks were applied in the main façade, whereas more irregular ones were used for secondary parts.

The northwest façade showed two barrel vaulted passages and a central entrance to the building. Other little rooms were located in the southern part of the complex. A squared outdoor area in the northern part was limited by the presence of a freestanding wall.

During the second half of the IV cent., an earthquake struck the area. The building was severely damaged and the central vault collapsed. The seismic event caused a moderate crack pattern on the pillars, but it was not so strong to cause their demolition. In this phase, new pillars were built close to the oldest structures (restored) by re-using collapsed blocks. The hall was thus reduced to $12 \mathrm{~m}$ of width and covered by cross or sails vaults. Vaulted passages were included inside new pillars. These modifications turned the building into a church in the Byzantine age (Figure $1 b$ ). The northern wall turned out to be part of a four-side portico and the southern rooms became the Presbyterian areas.

Moreover, the construction techniques worsened. Thicker layers of mortar were applied such as geometrical irregular blocks (obtained from first phase collapsed elements).

During the VI cent. an apse was added to the complex, after demolishing the southern wall of the hall. The plan of the apse was circular inside and polygonal outside (Mighetto \& Galvagno, 2012). A narthex was also added to the northern entrance.

During the centuries the complex was stricken by many other earthquakes, among them in the VII, X and XII cent. (Marabini, 2015), bringing it to its current configuration.

Today, compared to the original configuration of the complex, the building is subdivided by three main structural parts, quite well conserved (Figure 2a): 
the system of the western two arcades, supported by first phase pillars, second phase pillars, and the first level (5 metres high) of the northern façade (Figure 1a);

the eastern structural system composed by one-barrel double rings vault, first and second phase pillars and the perimeter eastern wall (that includes part of the main vault);

the northern freestanding wall.

Moreover, visitors today can see remains of the apse and of the southern rooms. Temporary shoring supports portions in unstable conditions (e.g. vaults, arches and wall overturning). Finally, collapsed blocks surround the remains of the complex, giving a suggestive outline of earthquake effects on ancient structures: the conservation of both of them (standing elements and collapsed blocks) is one of the purpose of an overall project of preservation of the intrinsic cultural value of the archaeological remains, which include the educational function of explaining the effects of seismic events (D'Andria 2007).
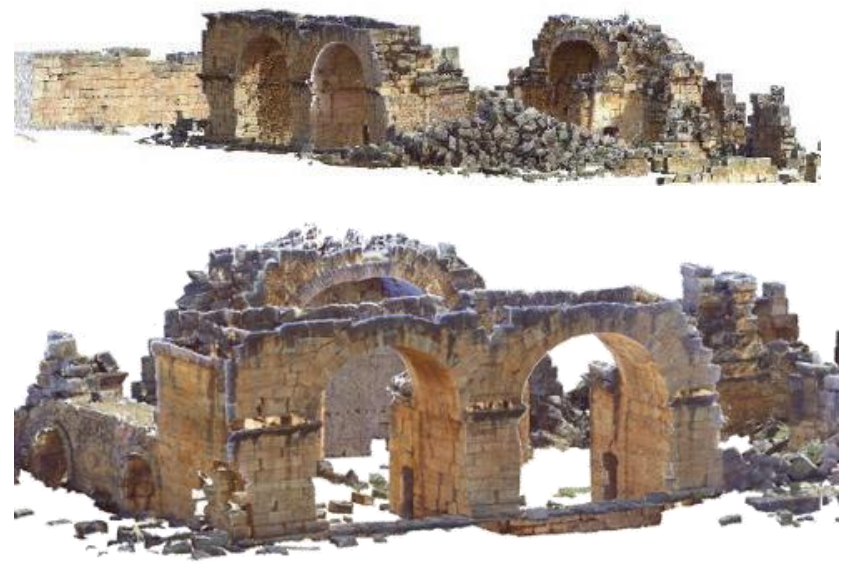

(a)

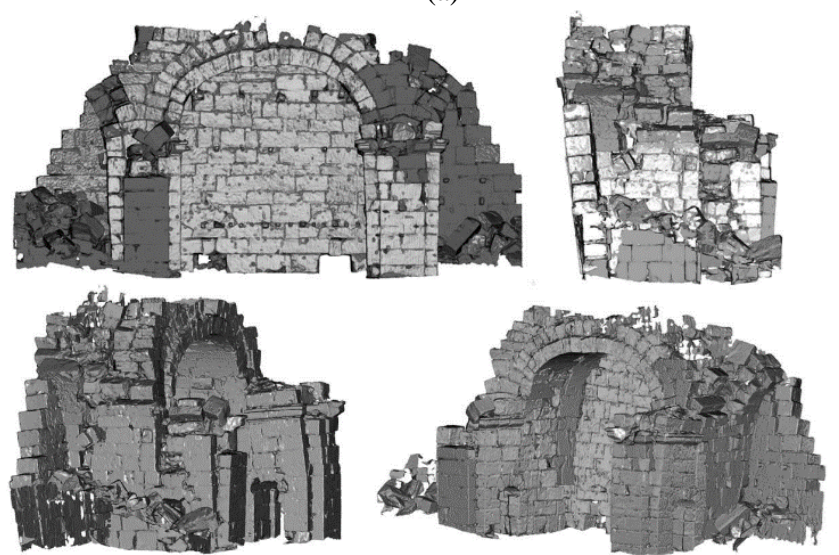

(b)



(c)

Figure 2. (a) Two general view of the overall LIDAR points cloud (b) the eastern structural system including one-barrel double rings vault, and first and second-phase pillars in some points cloud views; (c) the dimensioned architectural plan of the building. (Invernizzi, Spanò, Alferi, 2014)

\subsection{D integrated survey project (LiDAR and image based)}

The entire integrated LiDAR and photogrammetric survey has already been described (Spanò et al. 2016). Range data are 43 scans: a part acquired from the ground level, along the external perimeter of the building; other from the ground level inside the first phase hall; and few of them were performed by positioning the scanner at the top of some collapsed areas or on the top of easily accessible walls, in order to collect data as complete as possible. (resolution equal to $6 \mathrm{~mm}$ from each point to each other at the distance of $10 \mathrm{~m}$ ).

The use of a conspicuous set of control points, measured by total station from a topographical vertices network, despite the complexity of the building, its precarious conditions and the extensive collapses, allowed a recording of the scans with results in terms of RMSe ranging from half a centimeter to 1 $\mathrm{cm}$. The same control points were used to create first photogrammetric models using the SfM technique, and then orthophoto characterized by high resolutions (even $1 \mathrm{~mm}$ ) and RMSe near one or few centimeters.

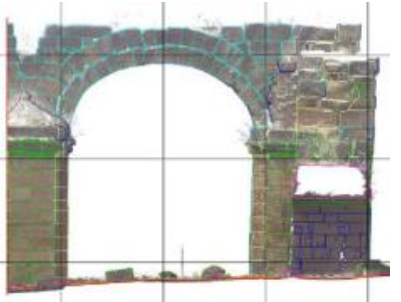

(a)

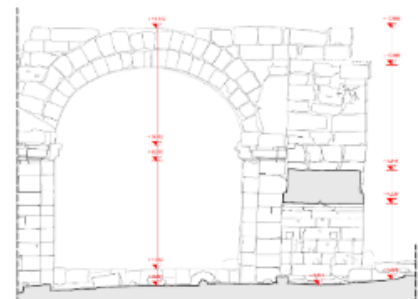

(b)
Figure 3. (a) An example of façade digitization using planar section of the 3D point cloud archive and (b) final architectural drawing.

The use of photogrammetry has been crucial and effective in order to integrate the radiometric rich contents of image based products in order to support both the macro-injuries than even finer readings material degradation through high resolution orthophotos.

Close-range images acquired in 2007 by a Panasonic DMCFZ50 $\mathrm{f}=7.4 \mathrm{~mm}$, featured by a sensor of $2560 \mathrm{x} 1920 \mathrm{px}$ have been processed by SfM approach for the image matching and $n^{\circ} 22$ 
topographic points (GCP) enabled a bundle block adjustment $\left(n^{\circ} 64\right.$ images) providing the quality results presented in table 1 .

\begin{tabular}{cc} 
& RMSE $(\mathrm{m})$ \\
\hline GCP & 0.023 \\
CP & 0.036
\end{tabular}

Table 1. Residual errors on the image block orientation

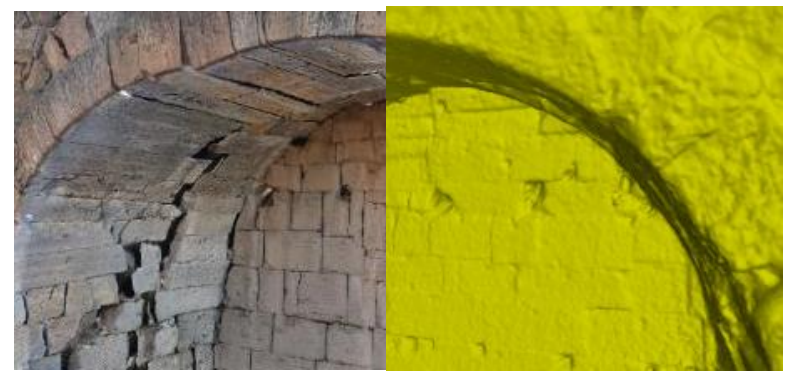

(a)

(b)

Figure 4 . The travertine blocks clearly legible in the triangulated mesh (b) computed from the dense 3D point cloud generated from an oriented images block; moreover, interpretable with high quality texture (a)

Figures 5 show a well interpretable comparison between descriptive capabilities of an SfM orthoimage and a LiDAR points cloud planar view: the search and detection of details whose identification is favoured by the light/shadow component of the images is certainly easier in the orthophoto of image based approach generation.

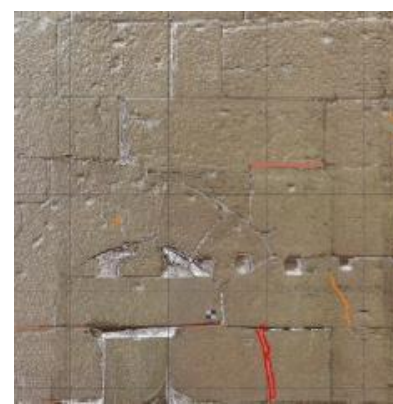

(a)

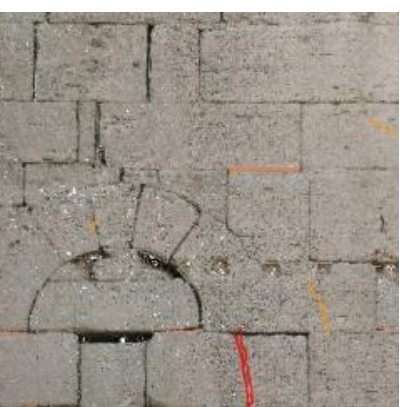

(b)
Figure 5. Degradation and cracking pattern superimposed to the different sensors orthoimages: TLS (a) and close-range imagematching (b)

The plotting of a profile and the conversion in a traditional architectural drawing is not simple and quick; the purpose to draw classical architectural plans and vertical sections request experience and proper skills of architectural shape reading, but can be highly supported by some automatic digitalization of blocks. The achievement of plan or section drawing can be highly supported by orthophotos or by means of tools providing mosaic of referenced and scaled images referring the cloud viewed as a projection in a certain plane. To achieve such goals, the software PointCab® has been managed. It produces the aforesaid data in a CAD environment file, that can be managed properly to achieve 2D architectural representation.

The digitalization attentive to degradation is extremely detailed, so the high degree of detail translates into the use of vector elements with a large number of vertices, which are appropriate for the structural and material degradation mapping (par 3.2), but which present an excess information for further analytical tests. The numerical simulation just achieved on a test masonries of the studied building (Invernizzi et al. 2014) has been based on FEM method and the metric survey drawings realized using LiDAR technology were the starting point for the definition of the discretized geometry necessary for the execution of the structural analyses.
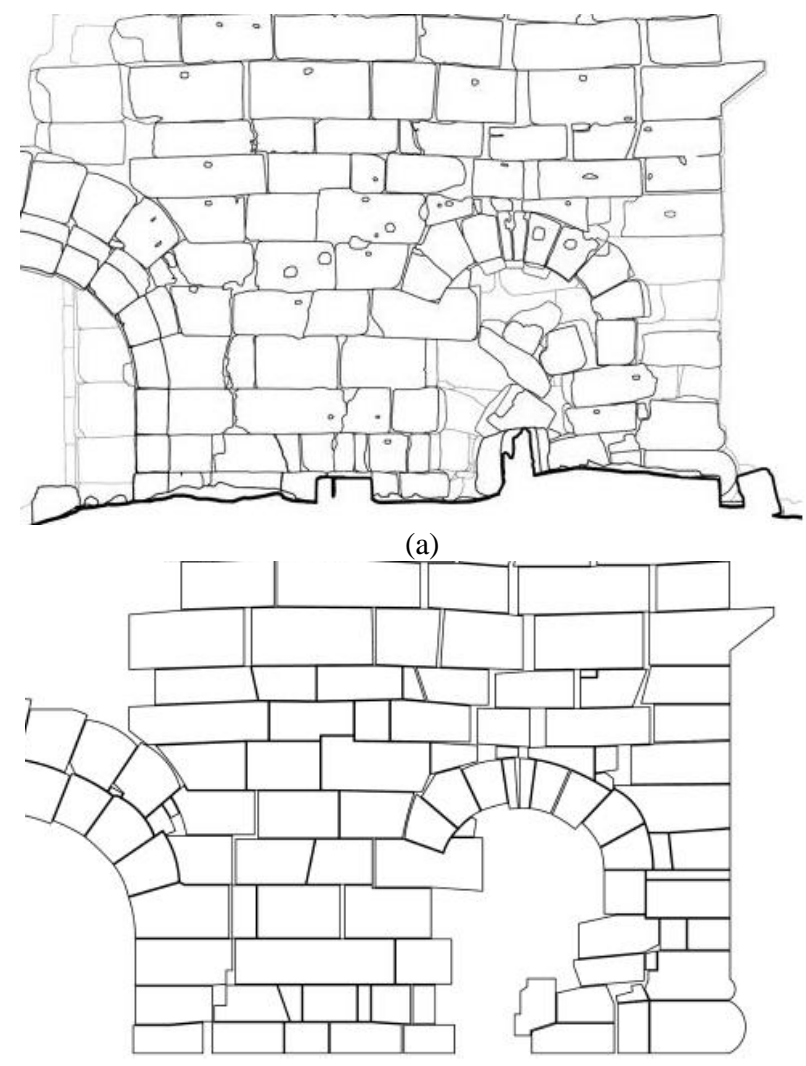

(b)

Figure 6. Different level of detail in (a) vectorialization of masonry blocks and in (b) discretized geometry for the structural analyses.

\subsection{Assisted detection and digitization of masonry blocks}

The use of LiDAR orthoimages from colorized point cloud is a well-established approach in the common operational phases of 3D survey applied on complex architectural sites and buildings. A test based on common edge detection algorithms applied on two different type of blocks images was performed, based on samples of the LiDAR orthoimages. The variances of the radiometric pattern and the richness of radiometric edges information cause complexities in the clear edge detection and extraction, and masonry block delineation as well known in literature for common operators (Maini\&Aggarwal, 2009).

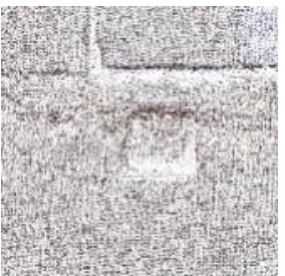

(a)



(a)

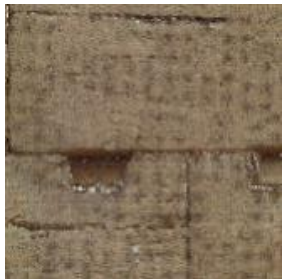

(b)
Figure 7. Digitalization of the LiDAR point cloud orthoprojection, with different rasterization resolution (PointCab inteface): $1 \mathrm{~mm} / \mathrm{px} 970 \mathrm{Mb} ; 5 \mathrm{~mm} / \mathrm{px}, 1.3 \mathrm{Mb}$; $1 \mathrm{~cm} / \mathrm{px}, 2.29 \mathrm{Mb}$ 


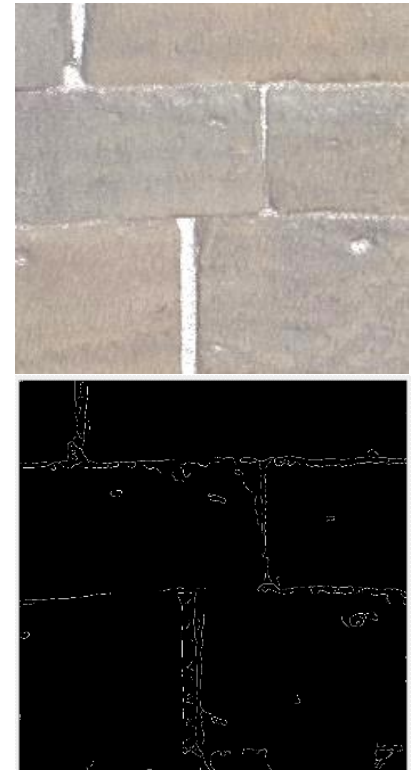

(a)

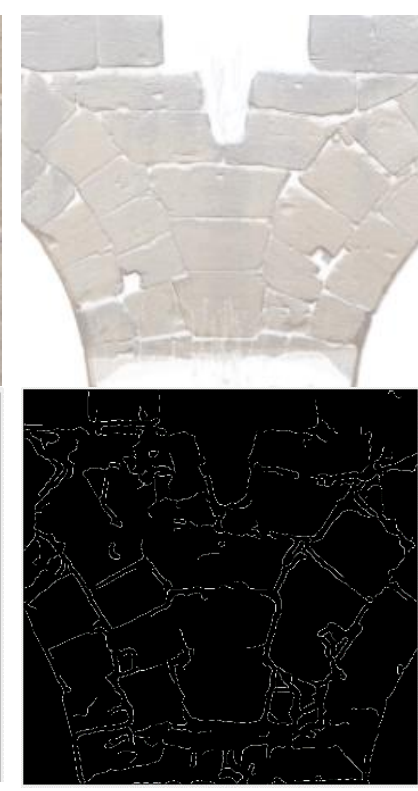

(b)

Figure 8. Test on edge detection algorithms applied on two different types of initial raster data referring to the blocks: algorithm applied to orthoimages: (a) raw and (b) processed for radiometric quality value balancing and contrast increasing.

In fact, the Canny, Prewitt and Sobel algorithms were tested on differently processed initial images, operating on the grayscale image and with varying threshold values of the edges extraction in terms of numbers of segments, continuity and noise values. In figure 8, the Canny algorithm (Rong et al, 2014) performance was tested based on a sample of raw orthoimage (figure 8a), and on a radiometrically processed orthoimage (figure $8 \mathrm{~b}$ ) for contrast increasing.

In the first simple case, the threshold of 0.2 was associated to a standard deviation (sigma) values of 3 : for this kind of image, smaller values caused strong noise effects and higher values lead to loss of edge extraction and continuity. The second case portraying multiple blocks in the extracted orthoimage, originates better results by the use of threshold $=0.2$ and 5 sigma.

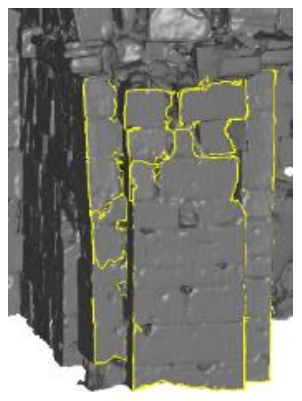

(a)
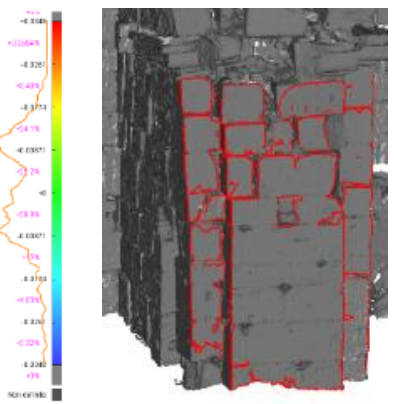

(b)

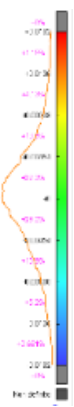

Figure 9. Digitalization with different level of triangulation details in mesh model

With regard to the application of feature detection and assisted digitization techniques starting instead from continuous surfaces (mesh), the generation of triangulated surfaces, namely the appropriate choice of the number of triangles and their size is essential to set up a case test that offers satisfactory results. (figure $9 \mathrm{a}, \mathrm{b}$ )

In figure 10, an application of the region growing algorithm for the identification of flat surfaces on the mesh of the architectural blocks is shown (using 3D Reshaper ${ }^{\circledR}$ by Hexagon interface). The variation in tolerance of the search for coplanar points allows the identification of the boundaries of the individual wall blocks, and the algorithm implementation is different if working on point cloud or continuous surfaces (figure 10). Here the extraction of blocks boundaries in an arch segment, is applied on the points cloud (figure 10a) and on mesh surface models, which also requires a further processing step (figure 10a). Both the detection from the cloud and the triangulated mesh is very accurate: for the points surface, $70 \%$ of the points from the original cloud deviate from detection plane for $\pm 4 \mathrm{~mm}$; slightly less accurate is the detection starting from the mesh, but the linearity of the profile and the number of vertices extracted is certainly more appropriate for the prearranged objectives, nearby $30 \%$ of the surface points from is encounter the detection plane for $\pm 5 \mathrm{~mm}$.

For an overall evaluation of the automatic travertine blocks delineation polygons from the mesh surface of the entire arch (black profiles in figure 10c), about $40 \%$ of the mesh vertices intercepted by the plane displays a difference from the reference mesh of less than $5 \mathrm{~mm}$, and generally for about $70 \%$ under $2 \mathrm{~cm}$.

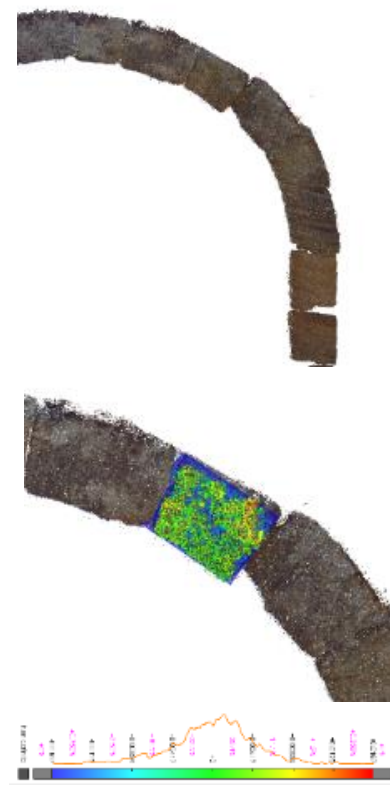

(a)
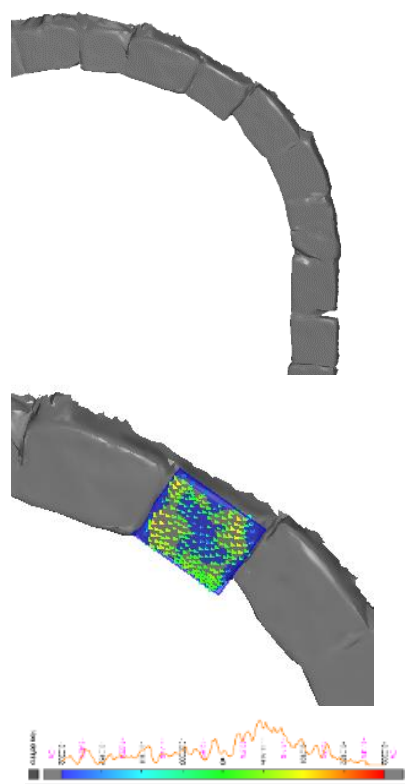

(b)
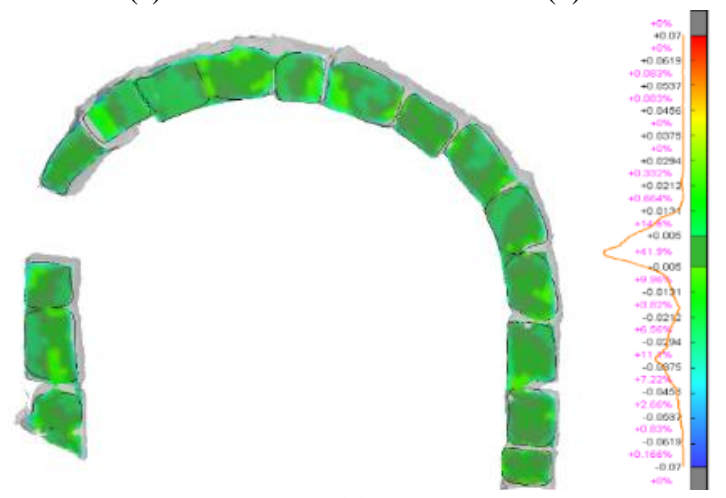

(c)

Figure 10. Blocks delineation profiles with region growing algorithm applied on 3D surface on the East side, for point cloud (a) and triangulated mesh (b). The comparison of derived polygons 
from mesh shows more than $40 \%$ of surface with a deviation from the reference mesh model minor than $5 \mathrm{~mm}$.

\subsection{Structural and material degradation mapping}

According to the architectural representations described in Par. 3.1 and 3.2, the survey phases of the Bath-Church were able to identify geometries, materials, structures, construction techniques, degradation, crack pattern and damage mechanisms. Here the method applied for the identification of structural elements and the material and degradation mapping is described for the north-western façade of the building.

Three Roman pillars, two Byzantine pillars, two double rings Roman vaults (Figure 11) and the northern façade, compose the structural system. It is built with travertine blocks lying on mortar layers of different thicknesses (thin for Roman parts, thick for Byzantine ones) and somewhere not preserved.

The façade (Figure 11), is a Roman phase structures., the vaults overcome $9 \mathrm{~m}$ of span, and reach almost $4 \mathrm{~m}$ of height above pillars $6.50 \mathrm{~m}$ high.

The deterioration map and cracking pattern showed in Figure 11 outline the progression of cracks, gaps and detachments. This constitutes the starting point for identifying parts involved in mechanisms of collapse, which can be local or global, already activated or potential.

In addition, the state of conservation of materials is investigated. In fact, bad condition contributes to weaken structural parts, for example through the presence of crust, cavities or, more often, vegetation.

The description adopted for the deterioration map follows Normal 1/88 recommendation and UNI 11182/2006.
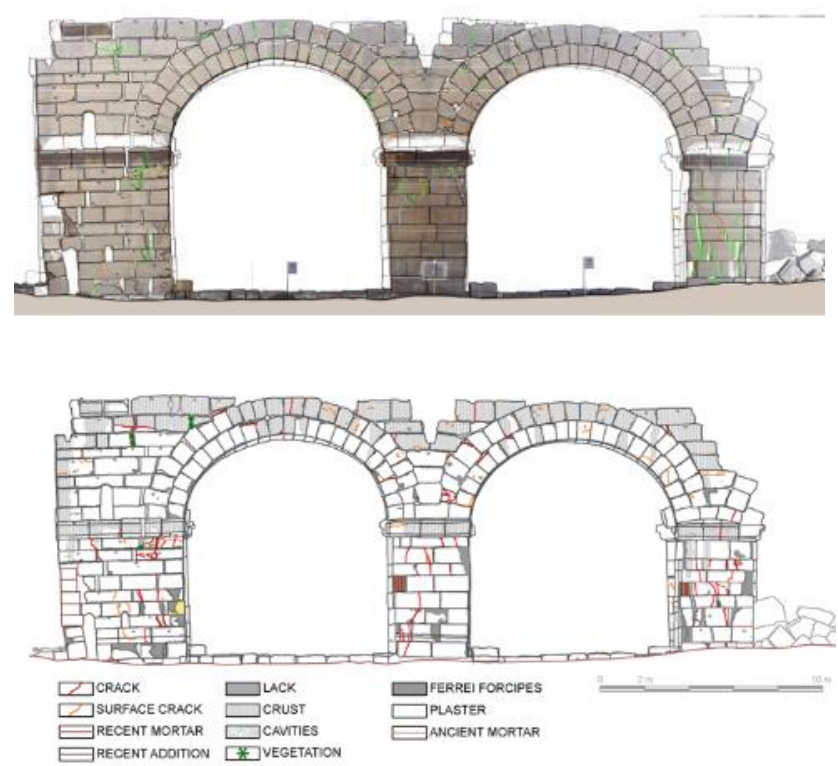

Figure 11. Deterioration map and cracking pattern of the northwestern façade.

The interpretation of the causes that led to the current configuration cannot disregard the analysis of the construction techniques applied. The Baths-Church are composed by a system of interlocked travertine blocks. The extended overlapping, possible thanks to the great dimensions of blocks, allows the structure maintaining equilibrium also in critical condition, such as widespread lacks (Figure 12) or considerable sliding between blocks. Obviously, when a block does not have a continuous supporting surface and the force exceeds its strength, a crack develops and the system could become unstable. Figure 12 (a) represents first condition, not evolved in collapse thanks to the integration of corner blocks Figure 12 (b).

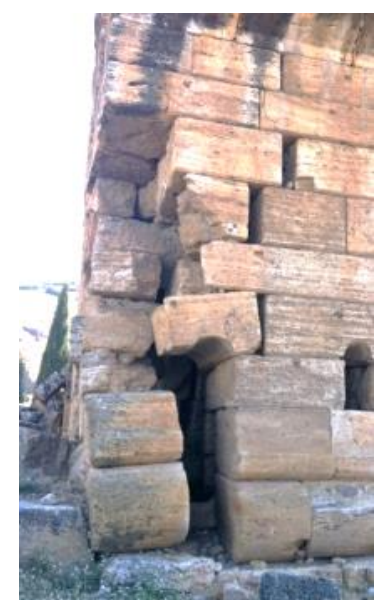

(a)

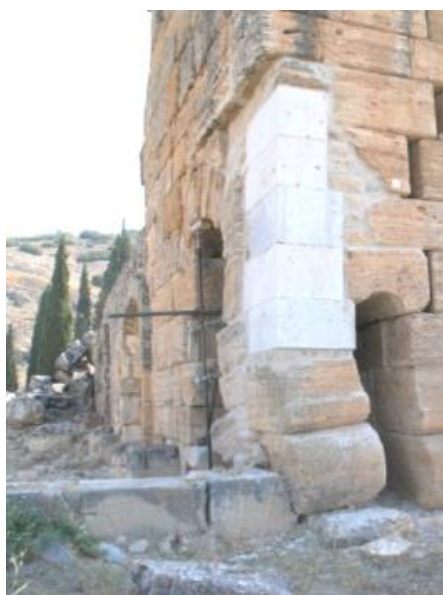

(b)
Figure 12. (a) lacks of blocks at the north-western corner and (b) more recent integration of blocks.

To complete the study of the construction technique and the evaluation of the state of conservation, the examination of the horizontality of the block support plane is presented in Figure 13. The colour scale indicates the degree of inclination of the block base, considering an ideal horizontal plane. Two cases are possible: i) alteration of the planar alignment during construction phases (consequent to irregularities on blocks dimensions), ii) deformations caused by seismic actions.

For example, the northern pillar (left one in Figure 13) blocks present inclined plane of $+2^{\circ}$ : the rotation of the springer caused the consequent deformation of the first vault. Moreover, the central and the right pillars present in their centre lines discordant angles and related widespread cracks.

The study of the horizontality of the block support plane also has a double prediction aim. In fact, it is a useful tool not only for identifying failure mechanisms, but it also evaluates the possible direction of blocks sliding, following the same inclination plane. At the presence of variation of inclination, they also identify surfaces of maximum stresses, where new cracks could open.

In the north-western façade, sliding between blocks reaches 16 $\mathrm{cm}$. The right spring of the southern vault has a drop of $14 \mathrm{~cm}$ less than the left one, causing a general deformation of its shape: the structural system is thus involved in a kinematic chain of collapse.



Figure 13. Deformation map. The color scale indicates the degree of inclination of the block base and its direction of possible movement. 
The integration of the evaluation of the conservation state, the crack pattern and the failure mechanisms allow for identifying kinematic portions for structural assessments of seismic vulnerability to be implemented in the calculation codes. For the façade in question, they are plotted in Figure 14.

The portions are composed by elements involved in the same structural behaviour.

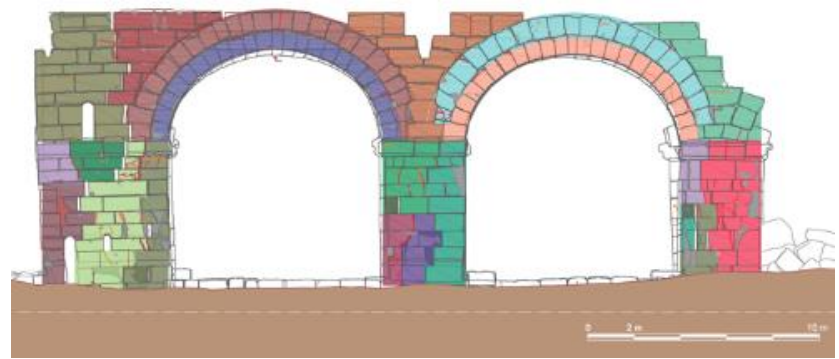

Figure 14. Identification of kinematic portion.

The process of analysis developed for the north-western façade can be then extended to the whole complex, involving $3 \mathrm{~d}$ evaluation of the structural behaviour, also linked to experimental tests.

Analytical models can be applied for the evaluation of static and seismic vulnerabilities. In this connection, the identification of parts composed by blocks that can react to seismic action as kinematic portions, characterised by monolithic behaviour, allows the application of the limit equilibrium analysis. Vice versa, the identification of a global behaviour (preferably supported by experimental tests results) allows for developing numerical models through FEM. Finally, (DEM) can be applied: the complex is represented as sum of each block subject to free-falling, bouncing, rolling, or sliding, according to laws of motion.

\section{CONCLUSION}

In this work, data collected from the geometrical survey were integrated by onsite visual inspection to represent the current condition of the Baths-Church complex. Starting from point clouds and orthophotos, the analyses provided:

a) deterioration map and cracking pattern: progression of lesions, gaps, detachments;

b) deformation map: analysis of the horizontality of the block support plane;

c) identification of kinematic portions for structural assessments of seismic vulnerability to be implemented in the calculation codes.

All that integrated information contributed to the identification of preliminary models able to evaluate the behavior of the artifact in its current conditions, to serve for simulations of the effects of suitable intervention measures for preservation against earthquakes.

From a methodological point of view, future developments are orienteered towards semiautomatic or automatic digitalisations and discretization, although it is certainly necessary to make greater efforts to try to introduce easy-to-use and accessible solutions into operational practice.

As future work, we promise to use lower resolution points clouds, namely derived from mobile mapping system (MMS) portable scanner and textured by high resolution oriented images, in order to evaluate its effectiveness for visual inspections of masonries, in addition to some piece of digitalization if the high accuracy and details are not requested.

\section{ACKNOWLEDGEMENTS}

The research has been carried out in the framework of the Italian PRIN 2015 project "Archeology of urban landscapes in Asia Minor between late Hellenism and Byzantine age. Multidisciplinary approaches to the study of Hierapolis in Phrygia" (national principal investigator G. Semeraro, local coordinators A. Spanò - Geomatics, M.R. Valluzzi Structural analyses).

\section{REFERENCES}

Adamopoulos, E.; Tsilimantou, E.; Keramidas, V.; Apostolopoulou, M.; Karoglou, M.; Tapinaki, S.; Ioannidis, C.; Georgopoulos, A.; Moropoulou, A. (2017). Multi-Sensor Documentation Of Metric And Qualitative Information Of Historic Stone Structures. ISPRS Ann. Photogramm. Remote Sens. Spat. Inf. Sci., IV-2/W2, 1-8.

Auer, S., Hinz, S. (2007). Automatic Extraction of Salient Geometric Entities from LIDAR Point Clouds.Proceedings of International Geoscience and Remote Sensing Symposium (IGARSS'07), Barcelona.

Castellazzi G., D’Altri A. M., Bitelli G., Selvaggi I., Lambertini A., (2015), From Laser Scanning to Finite Element Analysis of Complex Buildings by Using a Semi-Automatic Procedure, Sensors, 15, 18360-18380; doi:10.3390/s150818360.

Custodi A., Scaia F., (2016), The Augustan Bridge at Narni: From laser survey to FEM seismic analysis, Van Balen \& Verstrynge (Eds) Structural Analysis of Historical Constructions - Anamnesis, diagnosis, therapy, controls, Taylor \& Francis Group, London, ISBN 978-1-138-02951-4

D'Andria F (2007). Le attività della MAIER, Missione archeologica italiana 2000-2003, in D'andria F, Caggia P., (eds.), Hierapolis di Frigia I. Le attività delle campagne di scavo e restauro 2000-2003, Istanbul, 1-45.

D’Andria F., (2016) Cd. Terme Chiesa, in In Scardozzi G., Nuovo atlante di Hierapolis di Frigia. Cartografia archeologica della città e delle necropoli (Hierapolis di Frigia VII), Ege Yayinlari, Istanbul, $112-113$

Escarcena, J. C., de Castro, E. M., García, J. L. P., Calvache, A. M., del Castillo, T. F., García, J. D., \& Castillo, J. C. (2011). Integration of photogrammetric and terrestrial laser scanning techniques for heritage documentation. Virtual Archaeology Review, 2(3), 53-57. http://dx.doi.org/10.4995/var.2011.4605

Guardini N. (2014), 3D Survey and Modelling for structural analysis, $\mathrm{PhD}$ thesis, Università degli Studi di Firenze.

ICOMOS Charter on the Principles for the Analysis, Conservation and Structural Restoration of Architectural Heritage, Zimbabwe, October 2003

Invernizzi S., Spanò A., Alferi C. (2014) Combined Laser Surveying and Finite Element Modeling for The Structural Assessment of Masonry Structures at the Hierapolis Outer Bath Complex. In: 9th International Conference on Structural Analysis of Historical Construction SAHC2014, Mexico City, 15-17 Ottobre 2014

Korumaz, M.; Betti, M.; Conti, A.; Tucci, G.; Bartoli, G.; Bonora, V.; Fiorini, L. (2017). An integrated Terrestrial Laser Scanner (TLS), Deviation Analysis (DA) and Finite Element (FE) approach for health assessment of historical structures. A minaret case study. Engineering Structures, 153, 224-238. 
Lari Z., Habib A. F., Kwak E., (2011), An adaptive approach for segmentation of $3 d$ laser point cloud, ISPRS Archives, Volume XXXVIII-5/W12, pp 103-108.

Lerma, J.L (2005). Automatic plotting of architectural facades with multispectral images, Journal of surveying engineering, vol. 131, no. 3, pp. 73-77. DOI: 10.1061/(ASCE)7339453(2005)131:3(73)

Maini, R.; Aggarwal, H. (2009). Study and Comparison of Various Image Edge Detection Techniques. Int. J. Image Process. 3, 1-12.

Mighetto P., Galvagno F. (2012) Le Terme-Chiesa e la sfida della conservazione dei segni dell'attività sismica: $i$ primi interventi di messa in sicurezza e di consolidamento del complesso monumentale. in D'Andria $\mathrm{F}$, Caggia P., Ismaelli $\mathrm{T}$., (edd.) Hierapolis di Frigia V. Le attività delle campagne di scavo e restauro 2004-2006, Istanbul, 469-482.

Marabini S. (2015). La ricerca geo-archeologica a Hierapolis. In Scardozzi G., Nuovo atlante di Hierapolis di Frigia.Cartografia archeologica della città e delle necropoli (Hierapolis di Frigia VII), Ege Yayinlari, Istanbul, 227 -268.

Oses, N.; Dornaika, F.; Moujahid, A. (2014). Image-Based Delineation and Classification of Built Heritage Masonry. Remote Sens., 6, 1863-1889.

Patias P., Grussenmeyer P., Hanke.K., (2008). Applications in cultural heritage documentation. Advances in photogrammetry, remote sensing and spatial information sciences. 2008 ISPRS congress book. Vol. 7.

Remondino, F. (2011) Heritage Recording and 3D Modeling with Photogrammetry and 3D Scanning. Remote Sens., 3, 11041138 .

Riveiro B., Lourenço P.B., Oliveira D. V., González-Jorge H, Arias P., (2016) Automatic morphologic analysis of quasiperiodic masonry walls from LiDAR, in Comp.-Aided Civil and Infrastruct. Engineering DOI:10.1111/mice.12145

Rong W., Li Z., Zhang W., Sun L., (2014). An Improved Canny Edge Detection Algorithm, 2014 IEEE International Conference on Mechatronics and Automation, August 2014, pp.577-582. Doi: 10.1109/ICMA.2014.6885761

Pieraccini, M.; Dei, D.; Betti, M.; Bartoli, G.; Tucci, G.; Guardini, N. (2014), Dynamic identification of historic masonry towers through an expeditious and no-contact approach: Application to the "Torre del Mangia" in Siena (Italy). J. Cult. Herit., 15, 1-8.

Pierrot-Deseilligny, M.; De Luca, L.; Remondino, F. (2016) Automated Image-Based Procedures for Accurate Artifacts 3D Modeling and Orthoimage Generation. Geoinformatics $C T U$ FCE, 6, 291-299.

Sammartano, G.; Spanò, A.T. (2017) High scale 3D modelling and orthophoto of curved masonries for a multipurpose representation, analysis and assessment. Int. Arch. Photogramm. Remote Sens. Spat. Inf. Sci. - ISPRS Arch., 42, 245-252.

Shrestha, S., Reina Ortiz, M., Gutland, M., Napolitano, R., Morris, I. M., Santana Quintero, M., Erochko, J., Kawan, S., Shrestha, R. G., Awal, P., Suwal, S., Duwal, S., \& Maharjan, D. K. (2017). Digital recording and non-destructive techniques for the understanding of structural performance for rehabilitating historic structures at the Kathmandu valley after Gorkha earthquake 2015, ISPRS Ann. Photogramm. Remote Sens.
Spatial Inf. Sci., IV-2/W2, 243-250, https://doi.org/10.5194/isprs-annals-IV-2-W2-243-2017.

Spanò A., Chiabrando F., Bonfanti C., Alferi C., Invernizzi S., Vizzini C., (2016) Fotogrammetria e laser scanning per l'architettura antica. Il caso delle Terme-Chiesa, D'Andria F., Caggia P., Ismaelli T.(eds) Hierapolis Di Frigia VIII 1-2 Le Attivita delle Campagne di Scavo Restauro 2007-2011 (2 Vols.)

Teza G., Pesci A., Ninfo A. (2016) Morphological Analysis for Architectural Applications: Comparison between Laser Scanning and Structure-from-Motion Photogrammetry, Journal of Surveying Engineering 142(3), DOI: 10.1061/(ASCE)SU.1943-5428.0000172

Valluzzi M.R., Marson C., Taffarel S., Salvalaggio M., Deiana R., Boaga J. (2019) "Structural investigations and modelling of seismic behaviour on ruins in the monumental area of Hierapolis of Phrygia”. In: Aguilar R., Torrealva D., Moreira S., Pando M.A., Ramos L.F. (eds) Structural Analysis of Historical Constructions. An Interdisciplinary Approach. RILEM Bookseries, vol 18, pp. 1849-1857. Springer, Cham. Proc. of SAHC 2018 - 11th International Conference on Structural Analysis of Historical Constructions, Cusco (Peru), 11-13 September, 2018. https://doi.org/10.1007/978-3-319-994413_198.

Valutazione e riduzione del rischio sismico del patrimonio culturale con riferimento alle Norme Tecniche per le Costruzioni di cui al Decreto del Ministero delle infrastrutture e dei trasporti del 14 gennaio 2008, Direttiva del Presidente del Consiglio dei Ministri 9 febb. 2011, in Gazz. Uff. n.47 del 26 febb. 2011 - Suppl. ord. n. 54.

Valero E., Bosché F., Forster A., (2018). Automatic segmentation of $3 D$ point clouds of rubble masonry walls, and its application to building surveying, repair and maintenance, Automation in Construction, 96, 29-39.

Verzone P. (1956). Le chiese di Hierapolis in Asia minore, in CArch, VIII, 37-61. 